\title{
DESEMPENHO DO AMBIENTE CONSTRUÍDO COM TÉCNICA DE CONSTRUÇÃO COM TERRA: A TAIPA DE MÃO
}

\author{
BRAGA, Ingrid Gomes (1); \\ NASCIMENTO, Izabel Cristina M. de O. (2); \\ DUAILIBE, Andrea Cristina S. C. (3); \\ (1) Universidade Estadual do Maranhão, Doutora \\ e-mail: ingridbraga69@gmail.com \\ (2) Universidade Estadual do Maranhão, Mestranda \\ e-mail: izabel.nas13@gmail.com \\ (3) Universidade Estadual do Maranhão, Mestre \\ e-mail: andrea.duailibe@gmail.com
}

\begin{abstract}
RESUMO
Este artigo apresenta os estudos sobre a preservação das técnicas de construção da terra nas comunidades do Maranhão, os dados provêm da observação de seu uso atualmente. Defende o bom desempenho das técnicas de construção de terra usando a referência ABNT NBR 15575/2013, ou seja, Padrão de desempenho de edifícios residenciais, principalmente sobre manutenção, funcionalidade e acessibilidade. No final, destaca-se a importância de incorporar o conhecimento sobre essas técnicas no treinamento de arquitetos, pelo respeito e aplicação da "taipa de mão" em novas construções.
\end{abstract}

Palavras chave: desempenho; ambiente construído; construção com terra.

\begin{abstract}
This article presents the studies about preserving earth building techniques in communities of Maranhão, the data comes from the observation of its use currently. It defends the good performance of earth building techniques using ABNT NBR 15575/2013 reference, in other words, Standard of performance of residential buildings, mainly about maintainability, functionality and accessibility. At the end, stands out the importance of incorporating the knowledge about these techniques in the training of architects, for the respect and application of the "taipa de mão" in new constructions.
\end{abstract}

Keywords: performance; built environment; building with earth.

\section{INTRODUÇÃO}

$\mathrm{Na}$ atualidade, pode-se perceber o avanço nos modos de construir casas, sendo comum o uso de materiais como cerâmica, concreto, ferro, vidro, entre outros, nas residências de todas as camadas da sociedade. Estes materiais podem ser comprados livremente no mercado, não dependendo que o consumidor conheça suas propriedades técnicas e orientações de instalação, uso e manutenção. Essa "democratização de acesso" aos materiais de construção pode ser positiva, e garante o aumento da oferta de produtos no mercado e a baixa dos preços. Contudo, a falta de informação, que deveria ser fornecida pelos fabricantes, e a massificação de construções utilizando estes materiais contemporâneos, leva ao 


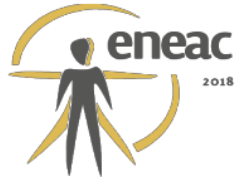

entendimento de que eles se aplicam a todas as condições climáticas e culturas brasileiras. As soluções construtivas e escolha de materiais precisam considerar que "toda pessoa tem uma história social, cultural e ambiental' (GONÇALVES, 2014) e carrega fatos, lembranças e relações importantes, e as habitações construídas em cada localidade precisam estar de acordo com estas especificidades.

A casa, como produto arquitetônico, vem apresentando mudanças em sua composição ao longo dos tempos. Ela reflete a cultura, a política e a sociedade de um determinado lugar, bem como o tempo histórico em que ela foi edificada (LEMOS, 1996; BONDUKI, 1994). Entretanto, projetar uma casa não pode se resumir a uma lista de cômodos que cada usuário acha necessário ter, e organizá-los dentro da lógica do arquiteto, seguindo orientações de livros e normas, e os materiais disponíveis no mercado. Além da casa ser a representação de quem nela habita e das experiências nela vivenciadas, sendo sempre carregada de significados (RIBEIRO, 2003), ela tem também grande valor enquanto abrigo e refúgio, como espaço que conforta e alivia as dores (GONÇALVES, 2014), devendo ser pensada inserindo estas necessidades subjetivas do usuário.

O profissional que desenvolve o projeto de uma casa, precisa entender que ela possui uma dinâmica cultural e social particular a cada grupo de usuários que vive a casa (LEMOS, 1996), e a elaboração do projeto deve levar isto em consideração. Falar em qualidade de uma casa é muito mais que descrever os materiais nobres ou populares que nela são aplicados, pois relaciona-se com as necessidades do indivíduo, podendo ser a localização, a acessibilidade, a privacidade, como também o conforto (TURNER, 1976). O projetista deve entender as funções dos espaços de cada moradia e de seus usuários, o comportamento de cada um que interage com seus espaços, e só então materializar estes ambientes, proporcionando assim um real conforto e satisfação aos usuários.

A casa antes pensada como "invólucro seletivo e corretivo das manifestações climáticas" (LEMOS, 1996), passa a ser testemunha de interações provenientes da cultura de quem nela habita, sendo uma referência de arquitetura que é símbolo da "concepção ideal de mundo" (RIBEIRO, 2003) daquele que nela é morador. O valor que este morador dará a casa que habita, não será decorrente apenas do valor de mercado que os materiais aplicados possuem, este valor é considerado quando a casa é eficiente frente às atividades desempenhadas em seu interior. Esta boa performance não está ligada apenas aos padrões arquitetônicos ou materiais aplicados, ela é variável quanto as prioridades de cada pessoa, e a mera demolição daquilo que o construtor acha inadequado, seguida da construção dos modelos impostos pelo mercado, não garantem solução de problemas relacionado aos modos de morar (TURNER, 1976). Em busca da "civilidade" da morada humana, foi imposto a casa a exigência de ser salubre para o corpo, a morada digna e de direito, inserida no planejamento da cidade com projetos de habitação (GONÇALVES, 2014; MARICATO, 2004), mas casa enquanto lar é também onde o indivíduo se permite ser ele mesmo e como tal precisa remeter a identidade individual.

O ambiente construído modela e é modelado pelo comportamento dos seus usuários, e um projeto descomprometido com as particularidades culturais e de clima, irá afetar a avaliação do seu desempenho (COSTA, 2016). Esta análise da eficiência de um ambiente, quando realizada do ponto de vista da ergonomia, deverá considerar, além do dimensionamento de móveis e elementos arquitetônicos, a resposta que os materiais utilizados darão quanto a atividade a ser desenvolvida no interior do ambiente (VILLAROUCO, 2002).

\section{A CASA NO BRASIL}

Na evolução do homem nômade para aquele que fixa moradia em um lugar e lá produz a terra para seu sustento é que surge a casa. Ela que se configura inicialmente pelo emprego de 


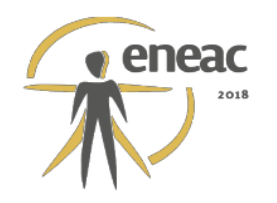

materiais da natureza, adaptando-se às condições climáticas, mas que assim, vai criando as particularidades de cada localidade. Apesar das afirmações de que as principais influências das moradias no Brasil vieram das construções das ocas indígenas e das casas portuguesas, que tinham o negro escravo como mão-de-obra da construção, em função das suas atividades de servidão, e como agente definidor das divisões internas da moradia (LEMOS, 1996), algumas outras técnicas, inclusive de influência africana, são comuns até hoje em grandes extensões do território brasileiro. Uma destas técnicas surgiu com a necessidade de controle da temperatura e umidade em regiões do país que possuem longos períodos de estiagem, levando a uma grande produção de casas de pau-a-pique, executadas com o complemento da técnica da taipa de mão (WEIMER, 2012). Na alvenaria de terra, encontram-se uma variedade de técnicas classificadas como adobe, bloco compactado e bloco prensado; paredes monolíticas, taipa-de-pilão, taipa-de-pilão reforçado e sistemas alternativos; e na família dos "entramados", estão a taipa e taipa pré-fabricada (NEVES, 2004). À parte, foram registradas técnicas, basicamente de uso restrito regional, que não se identificaram com a classificação adotada. A predominância do solo arenoso em alguns litorais brasileiros e margens de rio propiciou a construção de casas em palha, aproveitando a abundância das folhas provindas as palmeiras (WEIMER, 2012). Regiões alagadas, como mangues e pântanos, moldam a construção de casas de madeira sobre estacas, que é comumente chamada de palafitas. As características locais e os materiais que a natureza disponibiliza são, em boa parte do país, os elementos considerados pelas pessoas para construir suas casas, em uma mescla eficiente de respeito às necessidades pessoais e das condições impostas pela natureza

Mesmo as construções de imigrantes e colonizadores no Brasil seguiram este pensamento. Para as casas em "enxaimel", técnica construtiva tradicional, feitas pelos imigrantes germânicos, era extraída da natureza a madeira necessária para a construção e do solo os elementos para a vedação. Os italianos, localizados nas serras do país, valeram-se da abundância das pedras para execução do térreo e da madeira para a construção da casa sobre esta fortificação. As casas portuguesas quando construídas no Brasil mantiveram algumas características originais, contudo, devido peculiaridades locais como clima e economia, assumiram características particulares (LEMOS, 1996). Construídas por escravos também usavam a matéria prima local, com paredes mestras feitas de solo e cal, divisórias em adobe e taipa de mão, e barro cozido nos vãos de portas e janelas (MARANHÃO; BRASIL, 2008), sendo diferenciada das casas dos mais pobres apenas pela largura dos lotes, materiais de acabamento, tipologia e dimensões arquitetônicas (LEMOS, 1996; WEIMER, 2012). Apenas com a industrialização e abertura dos portos, iniciou-se a execução de casas com materiais de maior durabilidade, construções que foram se moldando à utilização das técnicas que conhecemos hoje. Com a revolução industrial vem então o emprego do "vidro, tintas, metais e cerâmicas" (MARICATO, 2004), materiais que se popularizaram e moldaram novos hábitos na população.

\section{ARQUITETURA E CONSTRUÇÃO COM TERRA}

As construções com terra existem antes mesmo da formação das primeiras cidades. Elas datam mais de 9.000 anos (MINKE, 2005), o que se justifica pela terra ser um material abundante em todos os lugares. As construções tradicionais, feitas com recursos da natureza possibilitaram espaços integrados com os aspectos térmicos, luminosos, acústicos que são inseparáveis em um espaço arquitetônico. Talvez devido ao baixo custo para se construir com terra ela muitas vezes seja relacionada a materiais de baixa qualidade, mas muitos monumentos históricos, erguidos a séculos, ainda se conservam.

A necessidade do mercado de estimular o consumo de produtos industrializados levou a maciças propagandas que acarretaram no desprezo e abandono de técnicas e materiais 


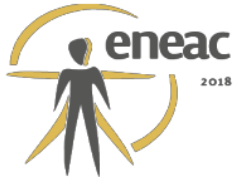

tradicionais pelas camadas mais abastadas da população. Contudo trouxeram consequências que levaram a necessidade de hoje se adotar soluções ambientalmente sustentáveis, com fins de minimizar os efeitos causados pela construção civil na produção do ambiente construído (MINTO, 2017). E sustentável deve ser compreendido como desenvolvimento orientado em direção à harmonia entre os âmbitos econômicos, sociais e ambientais. O setor da construção civil impacta o ecossistema, a economia e a sociedade. No processo de reversão desse quadro de descaso e ignorância, estudos acadêmicos têm o papel fundamental de produzir conhecimento sobre os saberes que a constituem, bem como o desenvolvimento conceitual e metodológico. As técnicas construtivas com terra e a arquitetura produzida com base na tradição e na vivência popular são, ao mesmo tempo, um recurso para o desenvolvimento socioeconômico e também um patrimônio cultural da maior importância.

A dimensão da arquitetura e construção com terra deve ser entendida por diferentes aspectos: pela dimensão histórica, como técnicas antigas e consagradas; pela dimensão política quando se refere à realidade de países em vias de desenvolvimento, aos quais não dispõem de recursos para investir em materiais industrializados; e pela dimensão social quando se refere aos processos de autoconstrução que podem ser uma resposta eficiente ao combate do déficit habitacional (MINTO, 2017). As ações do homem no processo de produção de bens de consumo, assim como da produção do espaço, causaram problemas ambientais que se tornaram evidentes ao final do século $X X$, o que resultou em uma sensibilização da sociedade para urgentemente reverter este quadro (NEVES e FARIA, 2011). A crise dos modelos de construção estabelecidos se instalou e, a arquitetura e construção com terra retorna como uma alternativa sustentável, incentivando a busca e a oferta para a formação e capacitação de profissionais preocupados em atender aos novos paradigmas. Como material natural, se torna uma alternativa às substâncias tóxicas dos materiais da construção civil da atualidade, garantindo qualidade no ar, atributo também por ser um material que "respira" (MINKE, 2005). Uma casa pode ser construída com materiais locais como a terra, e traz benefícios pela acessibilidade ao material e pelo sentido de autoconstrução e de coletividade.

Algumas vantagens da terra são o fato dela ser um material com boa capacidade de armazenamento térmico, apresentando eficácia em climas quentes ou frios, secos ou úmidos; possui capacidade de regular a umidade do ambiente construído, já que suas paredes absorvem toda a umidade em excesso, que posteriormente pode ser devolvida ao ambiente caso haja necessidade; é um material com uma boa reversibilidade e possibilita a economia de água e energia, já que ela necessita de apenas $1 \%$ a $2 \%$ da energia despendida numa construção convencional (MINKE apud MINTO, 2017). A alvenaria de adobe é uma das técnicas de construção mais primitivas e empregadas até hoje (NEVES e FARIA, 2011). Os adobes são fabricados por colocação manual da massa plástica, composta de terra e água, no interior de um molde apoiado em uma superfície plana, procedendo-se imediata desmoldagem. A taipa de pilão (ou simplesmente taipa) é outra técnica, conhecida no Brasil e Portugal, tapial ou apisonado são nomenclaturas utilizadas em outros países iberoamericanos, e correspondem a paredes monolíticas construídas no próprio local. São camadas de terra úmida compactadas no interior de moldes (taipal ou tapial), geralmente de madeira, que se deslocam à medida que avança a construção (MINKE, 2005). Outra técnica construtiva usada em várias regiões caracteriza-se pela combinação de madeira, bambu, varas, palha, fibras, com a terra e, eventualmente, aglomerante. Conhecida como taipa de mão, taipa de sopapo, pau a pique ou também taipa, no Brasil. A denominação geral do sistema é a de "técnica mista", mas devem ser conservados os usos de outras nomenclaturas regionais (REDE PROTERRA, 2017). 


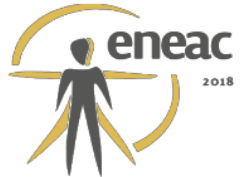

\subsection{Técnicas de construção com terra na zona rural do Maranhão: a taipa de mão}

A zona rural maranhense apresenta forte predominância de construções com taipa de mão, e boa parte do Estado tem domínio desta técnica tradicional (BURNETT e SOUZA, 2017). Há registros do uso desta técnica desde o séc. XVI, sendo ainda utilizada nos dias atuais, o que se justifica pela baixa renda da população que a utiliza, devido suas matérias primas serem encontradas na natureza, como também pelo conhecimento de usuários com melhor renda, já experientes com o uso de casas construídas com terra, sobre a qualidade do barro como controlador da temperatura e da humidade no interior das edificações (MINKE, 2001).

Construções mais atuais que vendem a ideia de emprego de novos materiais, estimulam o abandono de técnicas tradicionais que proporcionam construções mais adequadas a determinados climas, fazendo crer que estas não possuem qualidade, causando em muitas localidades o abandono das mesmas (BRAGA e NASCIMENTO, 2016). Em consequência disso, replicam modelos iguais em todas as localidades do país, sem que haja uma análise do seu contexto de uso e sem levar em consideração a experiência de uso. Os obstáculos em aceitar o valor da taipa de mão como método construtivo ultrapassam ideias preconceituosas quanto às patologias e transmissões de doenças (BURNETT e SOUZA, 2017), e muitas vezes fogem à necessidade de respeitar, preservar a identidade cultural das comunidades rurais do Maranhão e evitar os processos exógenos impositivos. A decisão de não oportunizar modelos de casa em taipa de mão e de impor opções em alvenaria (seja tijolo cerâmico ou blocos em concreto) representa bem mais do que abandonar uma técnica incorporada ao habitus construtivo, que se utiliza de materiais naturais, dispostos na maioria das vezes, no entorno dessas comunidades; trata-se de criar um movimento no sentido de rejeitar a padronização e a standardização com base em um protótipo imposto pelo mercado da construção civil e seus congêneres. Ignorar as idiossincrasias de uma comunidade rural, seus saberes e fazeres tradicionais, pode implicar na perda de sua autonomia e do caráter identitário.

As políticas habitacionais, o mercado imobiliário e os agentes financiadores pressionam para o uso massivo do tijolo cerâmico e da alvenaria estrutural, métodos relativamente tradicionais de construção, cujo foco é a rapidez na execução e a pouca necessidade de especialização de mão de obra. Seguem um tipo arquitetônico arcaico, que guarda grande similitude com os modelos praticados desde a era BNH (Banco Nacional de Habitação), tanto nas soluções horizontalizadas, como nas verticalizadas. A diferença está na escala e no impacto desses empreendimentos no meio. As imagens aéreas não deixam dúvidas quanto a isso, com repercussões do ponto de vista urbanístico, também. Porém, essa abordagem será deixada para uma próxima oportunidade. As zonas rurais do Maranhão são as mais afetadas pelos programas habitacionais justamente por produzir um modelo de casa que não leva em conta as diversas funções que ela tem para a população rural. O modelo imposto obriga os novos moradores a instituir novos vínculos sociais o que leva ao comprometimento da sobrevivência cultural local (BURNETT, 2017), bem como a mudança das dinâmicas ligadas a casa, pois para eles estas edificações são pequenas e não possuem dimensões, e soluções arquitetônicas condizentes com as suas necessidades.

\section{O DESEMPENHO DO AMBIENTE CONSTRUíDO COM TÉCNICA DE CONSTRUÇÃO COM TERRA: A TAIPA DE MÃO}

A passagem do processo construtivo artesanal para o industrial se justificou por parâmetros que regem cada caso particular, como as necessidades da sociedade, as bases técnicas e científicas existentes, as políticas de desenvolvimento, as considerações socioeconômicas e culturais, investimentos e procedimentos de trabalho (NEVES, 2004). Estas mudanças acabaram refletindo no espaço que é construído, e consequentemente no desempenho dele frente às atividades desenvolvidas em seu interior. Sendo o ambiente construído um "cenário 
social de naturezas e interfaces diversas, que propiciam múltiplas interações aos usuários" (RANGEL e MONT'ALVÃO, 2015), o estudo deste espaço deve levar em consideração tanto os aspectos técnicos quanto aqueles particulares a cada realidade social, econômica e cultural.

Para este trabalho, está sendo considerado o espaço construído para moradia e o desempenho dele, quando executado a técnica de construção com terra, conhecida como taipa de mão, e que é comum na zona rural maranhense. Em muitas localidades no Maranhão, tem-se substituído, com o avanço de programas de habitação e difusão de materiais industrializados, as construções com terra pelas alvenarias estruturais e de tijolo cerâmico, o que acaba interferindo em tarefas desempenhadas cotidianamente pelos usuários, como também em questões de conforto, a exemplo do controle da temperatura interna, o controle higrotérmico no interior dos espaços (MINKE, 2001), e, principalmente, na capacidade do usuário em manter este sistema em funcionamento. Os usuários, muitas vezes, não possuem condições financeiras para custear ampliações e manutenções, como também, em muitas situações, não possuem conhecimentos técnicos para eles mesmos executarem os serviços, diferente do que acontecia em construções onde a matéria-prima é a terra.

Dentre os princípios do design usável está a "prevenção de erros e correção" (JORDAN, 1998), que no design de um ambiente construído pode ser considerado para a ambientes onde o usuário tem autonomia para manutenção dos espaços. Um outro tópico é o "controle do usuário", que para este trabalho justifica-se pela construção de espaços possíveis do próprio usuário realizar reformas, ampliações e melhorias. Quando uma edificação contempla estes princípios ela permite que seja cumprido com um dos requisitos para um bom desempenho de uma edificação que é a sua "manutenbilidade" (NBR 15575, 2013). Ela faz referência a atividades que devem ser realizadas para conservar a capacidade funcional de um ambiente inserindo o usuário nesta atividade. Outro requisito atendido é a "funcionalidade e acessibilidade" (NBR 15575, 2013), que refere-se ao dimensionamento de uma construção considerando usuários com deficiência e mobilidade reduzida, mas também a capacidade do próprio usuário realizar as ampliações sem prejuízo do desempenho da edificação.

Partindo deste entendimento, um ambiente construído deve ser usável, ou seja, deve possuir elementos e características apropriadas para a execução das atividades em seu interior, necessitando, contudo, da existência de "condicionantes físicos, cognitivos, antropométricos, psicossociais, e culturais" (VILLAROUCO; ANDRETO, 2008). No caso das construções em taipa de mão, para que tenham durabilidade, são importantes o projeto, a construção e a manutenção. A seleção dos materiais e os processos inerentes a esta técnica devem ser equilibrados de modo à obtenção de um limite considerado próximo ao ideal, com níveis de qualidade, e que se apresentem na textura, plasticidade, retração, compressibilidade, coesão, aspectos fundamentais para resultado final deste tipo de construção. A história vem demonstrando que construções em terra são duráveis e adaptáveis a situações diversas.

\subsection{O desempenho de casas de taipa na zona rural do Maranhão}

O curso de Arquitetura e Urbanismo, da Universidade Estadual do Maranhão, tem desenvolvido estudos das técnicas tradicionais de construção no Estado, através de atividades teórico-práticas em sala de aula e atividades de extensão. Para este trabalho será apresentada a casa rural feita com taipa de mão, usando como exemplo a comunidade quilombola Canelatiua, no município de Alcântara, pois ela possui grande conhecimento e domínio desta técnica. Apesar desta comunidade possuir construções com materiais industrializados, chamadas aqui de casa de projeto, executados por programas sociais, ela mantém as construções antes feitas em terra e, em alguns casos, edificam novas construções com a técnica aprendida de geração em geração e que é comum na região. A partir da utilização da técnica de observação simples, pois não objetivou testar uma hipótese (GIL, 
2008), mas sim ter um caráter exploratório de conhecimento das construções tradicionais e da relação delas com cada usuário, algumas visitas à comunidade e conversas com moradores, demonstraram aspectos da construção com terra que podem ser relacionadas às informações técnicas da Norma de Desempenho (Tabela 1).

Tabela 1 - A taipa de mão e os elementos da norma de desempenho.

\begin{tabular}{|c|c|c|}
\hline \multicolumn{2}{|c|}{$\begin{array}{l}\text { ABNT NBR 15575/2013 } \\
\text { (CBIC, 2013) }\end{array}$} & \multirow{2}{*}{$\begin{array}{c}\text { CONSTRUÇÃO COM TAIPA DE MÃO } \\
\text { Minke (2001) e experiência dos } \\
\text { usuários }\end{array}$} \\
\hline \multirow{11}{*}{ REQUISITOS GERAIS } & Implantação da obra & \\
\hline & Saúde, higiene e qualidade do ar & $\begin{array}{l}\text { Material com pouca variação de } \\
\text { umidade. A parede "respira". }\end{array}$ \\
\hline & $\begin{array}{l}\text { Localização, tipo e dimensões das } \\
\text { aberturas de portas e janelas }\end{array}$ & Igual a outros materiais \\
\hline & $\begin{array}{l}\text { Acabamento de coberturas, fachadas e } \\
\text { janelas devem propiciar estanqueidade }\end{array}$ & Igual a outros materiais \\
\hline & $\begin{array}{l}\text { Instalações de água e esgoto com } \\
\text { obediência as normas brasileiras }\end{array}$ & Igual a outros materiais \\
\hline & \multirow{3}{*}{ Adequação ao ambiente } & $\begin{array}{c}\text { Consumo racional, baixa degradação } \\
\text { ambiental, baixo consumo de matéria } \\
\text { prima }\end{array}$ \\
\hline & & Inexistência de resíduos \\
\hline & & $\begin{array}{l}\text { Baixo consumo de energia elétrica } \\
\text { durante o uso. }\end{array}$ \\
\hline & Racionalização do consumo de água & Igual a outros materiais \\
\hline & $\begin{array}{l}\text { Risco de contaminação do solo e do } \\
\text { lençol freático }\end{array}$ & Igual a outros materiais \\
\hline & Utilização e reuso da água & Igual a outros materiais \\
\hline $\begin{array}{l}\text { DESEMPENHO } \\
\text { ESTRUTURAL }\end{array}$ & Estabilidade e resistência & $\begin{array}{c}\text { Podem ser utilizados os mesmos } \\
\text { sistemas estruturais }\end{array}$ \\
\hline \multirow{2}{*}{$\begin{array}{l}\text { SEGURANÇA } \\
\text { CONTRA INCÊNDIO }\end{array}$} & Propagação de incêndio & Material não combustível \\
\hline & Sinalização e facilidade de fuga & Igual a outros materiais \\
\hline $\begin{array}{l}\text { SEGURANÇA NO USO } \\
\text { E NA OPERAÇÃO }\end{array}$ & Utilização de sistemas prediais & Igual a outros materiais \\
\hline
\end{tabular}




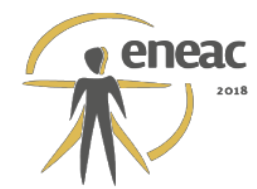

\begin{tabular}{|c|c|c|}
\hline FUNCIONALIDADE E & $\begin{array}{c}\text { Definição em projeto quanto pé direito, } \\
\text { dimensionamento de espaços, } \\
\text { adequações a pessoas com deficiência } \\
\text { e mobilidade reduzida, instalações } \\
\text { prediais. }\end{array}$ & Igual a outros materiais \\
\hline & $\begin{array}{c}\text { Ampliação de unidades habitacionais } \\
\text { evolutivas }\end{array}$ & $\begin{array}{c}\text { Utiliza recursos regionais e os usuários } \\
\text { já possuem conhecimentos técnicos } \\
\text { para realizar ampliações e } \\
\text { manutenções. }\end{array}$ \\
\hline $\begin{array}{l}\text { CONFORTO TÁTIL E } \\
\text { ANTROPODINÂMICO }\end{array}$ & $\begin{array}{l}\text { Planicidade de pisos, dispositivos de } \\
\text { manobra, adaptação ergonômica de } \\
\text { acionadores. }\end{array}$ & Igual a outros materiais \\
\hline $\begin{array}{l}\text { DESEMPENHO } \\
\text { TÉRMICO }\end{array}$ & Transmitância térmica & Controle eficiente de temperatura \\
\hline $\begin{array}{l}\text { DESEMPENHO } \\
\text { ACÚSTICO }\end{array}$ & $\begin{array}{l}\text { Isolação sonora de fachadas e paredes } \\
\text { internas }\end{array}$ & Bom desempenho acústico \\
\hline $\begin{array}{l}\text { DESEMPENHO } \\
\text { LUMÍNICO }\end{array}$ & Níveis de luminância natural e artificial & Igual a outros materiais \\
\hline $\begin{array}{l}\text { ESTANQUEIDADE A } \\
\text { ÁGUA }\end{array}$ & $\begin{array}{l}\text { Estanqueidade de fachadas e paredes } \\
\text { internas }\end{array}$ & $\begin{array}{l}\text { Material permeável, necessita de } \\
\text { revestimento para impermeabilização. }\end{array}$ \\
\hline DURABILIDADE & Durabilidade da edificação habitacional & Pouco durável. \\
\hline MANUTENIBILIDADE & Uso, operação e manutenção & $\begin{array}{l}\text { O usuário conhece a técnica e o } \\
\text { material. } \\
\text { Necessidade de manutenção constante, } \\
\text { contudo seus resíduos são reutilizáveis. }\end{array}$ \\
\hline
\end{tabular}

Fonte: Adaptado pelas autoras.

Em muitos aspectos a construção com taipa de mão não difere-se de outros materiais, pois cuidados com a implantação, posicionamento da edificação, dimensões de vãos e esquadrias, instalações prediais e acabamentos são tão possíveis de utilização neste tipo de construção quanto naquelas realizadas com emprego de materiais industrializados. A construção com terra não pode ser executada em contato com o solo, pois possui grande permeabilidade (MINKE, 2001; MINTO, 2017), mas isto pode ser resolvido adaptando-se a altura da fundação. No caso de outros materiais menos permeáveis, apesar de não necessitar de alteração no nível da fundação, faz-se necessária a impermeabilização na base das alvenarias.

Quanto a salubridade e qualidade do ar, a construção com terra realiza um eficiente controle da umidade. "Paredes de terra transpiram e equilibram os excessos e as carências de umidade e temperatura do meio ambiente" (WEIMER, 2012). Ela possui também a qualidade de não fornecer resíduos tóxicos para o ar, pois toda a sua composição foi extraída da natureza e principalmente, da vegetação do entorno. Isto garante uma outra vantagem se comparada a outros materiais de construção, pois não há a necessidade de gestão de resíduos já que ela retorna ao meio ambiente sem prejuízos para ele. Apesar da pouca durabilidade, a sua utilização no Maranhão justifica-se pelo domínio que as comunidades possuem das técnicas construtivas, permitindo a realização de manutenções e consertos pelos próprios usuários.

Uma importante característica que influencia no desempenho de construções em terra, é que, por ela ser uma técnica tradicional e de muitas comunidades terem conhecimentos sobre seus 


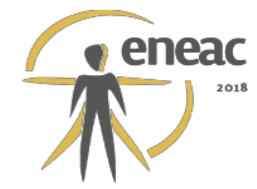

métodos construtivos, elas são comuns em edificações autoconstruídas (MINTO, 2017), e muitas vezes não seguem um padrão, moldando-se a cada morador. Elas são executadas por cada usuário dentro de requisitos considerados importantes para as suas próprias necessidades, que podem não ser aqueles determinados nas normas (Figura 1).

Figura 1 - Casa de taipa de mão e casa de projeto.

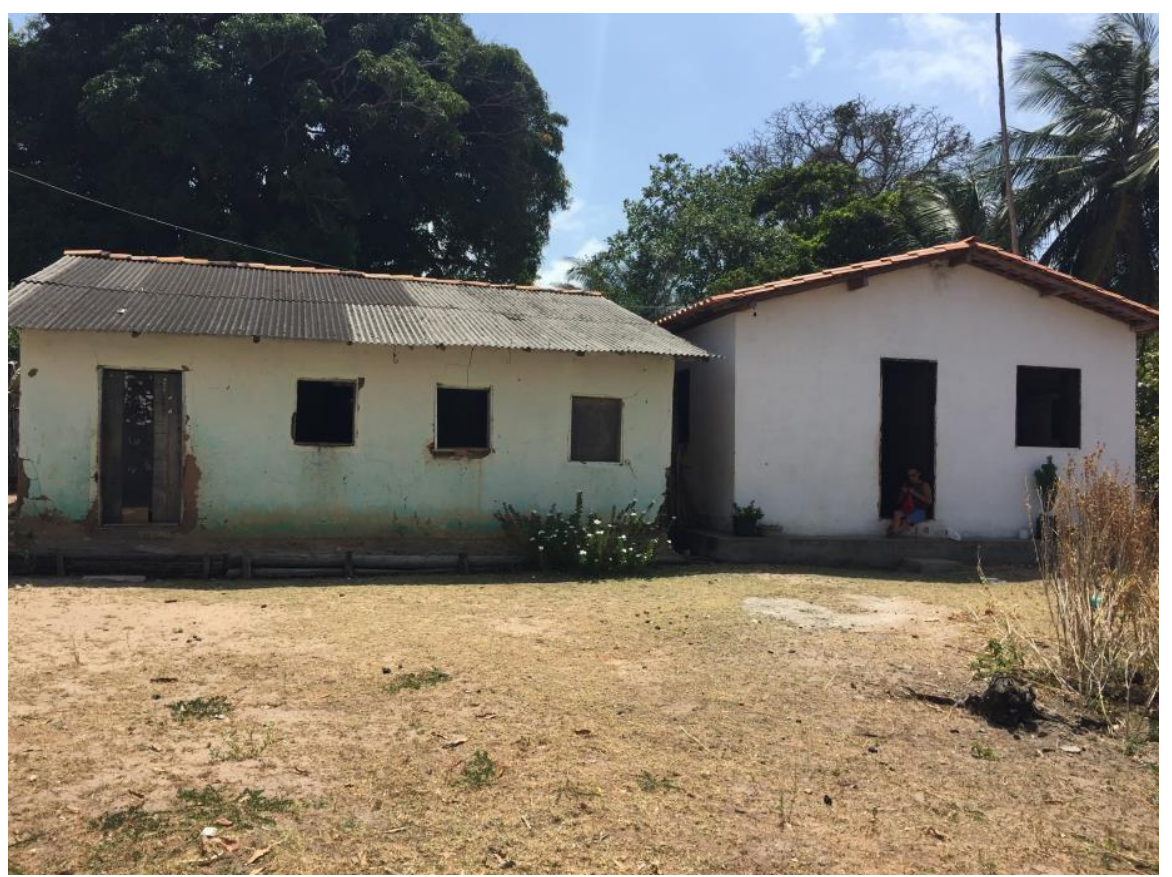

Fonte: Produzida pelas autoras (2017)

Muitas casas construídas em alvenaria não atendem às necessidades de seus usuários, assim, eles mantém a casa que possuíam anteriormente e, muitas vezes, constroem anexos, nas casas de projeto, com as técnicas que eles dominam, a taipa de mão, seja pelo baixo custo da construção ou pela atividade que será desempenhada no interior. O desempenho destas edificações depende do atendimento que elas fazem frente às necessidades particulares de cada morador.

\section{CONSIDERAÇÕES FINAIS}

O desempenho de um ambiente construído não depende apenas dos requisitos cumpridos com uso dos materiais disponíveis no mercado, mas da capacidade que estes materiais possuem para suprirem as necessidades dos usuários e contribuírem na qualidade da relação que uma pessoa possui com o ambiente em que desempenha suas atividades. Quando se avalia uma moradia, é ainda mais necessário, considerar fatores subjetivos, sociais, econômicos e culturais, pois os ambientes serão utilizados para atividades particulares a cada pessoa. Em povoados do Maranhão, os hábitos e conhecimentos técnicos sobre construções em taipa de mão influenciam na análise do desempenho, pois em muitos casos não correspondem às necessidades pós-ocupacionais de manutenção e ampliação.

Outros fatores que garantem o bom desempenho das construções com terra é a sustentabilidade do sistema construtivo que extrai matéria-prima da natureza, sem altera-la, de maneira que esta pode retornar ao meio ambiente sem prejuízo do mesmo. Isto garante 


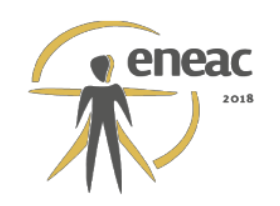

também economia para os usuários por dispensar gastos com transporte de material, que neste caso é extraído no entorno, e em caso de demolição, os materiais não precisam ser destinados a outro local, pois mesmo depois de utilizados em construção os materiais readquirem suas condições originais quando devolvidos à natureza (WEIMER, 2012).

Incorporar o conhecimento de técnicas de construção com terra no ambiente acadêmico, irá contribuir na formação de arquitetos conhecedores dos benefícios da manutenção desta técnica tradicional, e do valor sociocultural que ela possui em localidades como o Maranhão, bem como amplia estudos para a melhoria e utilização destas técnicas em outros projetos executados no Estado, ou propostos em regiões com características semelhantes. Contribui também no entendimento de que, apesar das normas trazerem requisitos que devem ser seguidos, que incluem materiais e padrões de arquitetura, a qualidade no desempenho dependerá também do entendimento sobre as prioridades e cultura dos moradores.

\section{REFERÊNCIAS BIBLIOGRÁFICAS}

BONDUKI, Nabil G. Origens da habitação social no Brasil. Análise Social, v. XXIX (127), 1994, p. 711732.

BRAGA, Ingrid G.; NASCIMENTO, Izabel C. M. O. Técnicas Construtivas Tradicionais como práticas acadêmicas para um habitar sustentável. I Seminário Nacional de Pesquisas e Estudos sobre as Cidades: espaços, atores e dinâmicas no nordeste do Brasil. São Bernardo/MA, set. 2016.

BURNETT, Carlos F. L; SOUZA, Clara R. P. de. Valorização da moradia rural de taipa de mão no Maranhão, Brasil. p. 615-627. In: Memorias del 170 Seminário Iberoamericano de Arquitectura y Construcción com Tierra. La Paz: FAADU-UMSA/ PROTERRA, 2017.

CÂMARA BRASILEIRA DA INDÚSTRIA DA CONSTRUÇÃO - CBIC. Desempenho de edificações habitacionais: guia orientativo para atendimento à norma ABNT NBR 15575/2013. Fortaleza: Gadioli Cipolla Comunicação, 2013.

COSTA, Ana P. L. Por uma interseção entre a ergonomia e o projeto de ambientes construídos, p. 1416. In: Anais do VI Encontro Nacional de Ergonomia do Ambiente Construído e VII Seminário Brasileiro de Acessibilidade Integral, v.2 n.7. São Paulo: Blucher, 2016.

GIL, Antonio C. Métodos e técnicas de pesquisa social. 6 ed. São Paulo: Atlas, 2008.

GONÇALVES, Teresinha M. Habitar: a casa como contingência da condição humana. Revista invi, n.80, v. 29, mai-2014, p. 83-108.

LEMOS, Carlos A. C. A casa brasileira. São Paulo: Contexto, 1996.

MARICATO, Ermínia. Habitação e Cidade. 7 ed. São Paulo: Editora Atual, 2004.

MINTO, F. C. N.; SILVOCO, M. M.; CARVALHO, B. T. (2017). Ensino da arquitetura e construção com terra na FAU/UFRJ, Rio de Janeiro, Brasil. Seminario Iberoamericano de Arquitectura y Construcción con Tierra, 17 Memorias... La Paz, Bolivia: PROTERRA/FAADU-UMSA. p. 456-464.

MINKE, Gernot. Manual de construccion en tierra: la tierra como material de construcción y su aplicación en la arquitectura actual. Montevideo: Editorial Fin de Siglo, 2005.

NEVES, Célia Maria Martins (2004). Resgate e Atualização do construir com terra: 0 Projeto PROTERRA. I Conferência Latino-Americana de Construção Sustentável X Encontro Nacional de Tecnologia do Ambiente Construído 18-21 julho 2004, São Paulo. ISBN 85-89478-08-4

RANGEL, Marcia M.; MONT'ALVÃO, Claudia. A observação do comportamento do usuário para o 


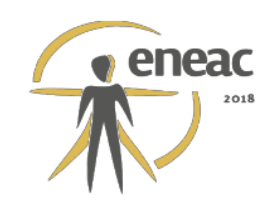

wayfinding no ambiente construído. Estudos em Design (online). v. 23, n. 3. Rio de Janeiro,2015. p. $166-180$

RIBEIRO, Cláudia R. V. A dimensão simbólica da arquitetura: parâmetros intangíveis do espaço concreto. Belo Hrorizonte: FUMEC, FACE, C/ Arte, 2003.

TURNER, John F. C. Housing by people: towards autonomy in building environments. London and New York: Marion Boyars, 1976.

VILLAROUCO, Vilma. Avaliação ergonômica do projeto arquitetônico. In: Anais do XII Congresso Brasileiro de Ergonomia, VI Congresso latino-americano de Ergonomia e I Seminário Brasileiro de Acessibilidade Integral. Recife, 2002.

VILLAROUCO, Vilma; ANDRETO, Luiz F. M. Avaliando desempenho de espaços de trabalho sob o enfoque da ergonomia do ambiente construído. Produção, v.18, n.3, set-dez, 2008, p. 523-539.

WEIMER, Günter. Arquitetura popular brasileira. 2 ed. São Paulo: Editora WMF Martins Fontes, 2012.

\section{REFERÊNCIAS ELETRÔNICAS}

NEVES, Célia; FARIA, Obede Borges (Org.) (2011). Técnicas de construção com terra. Bauru, SP: FEB-UNESP/PROTERRA, 2011. 79p. Disponível em: http://www.redproterra.org

PONTE, Maria M.C.C. Arquitetura de Terra: o desenho para a durabilidade das construções. 2012. Disponivel https://estudogeral.sib.uc.pt/bitstream/10316/23293/1/ARQUITETURA\%20DE\%20TERRA\%20\%20Maria\%20Manuel\%20Ponte.pdf

RED PROTERRA. (2017). Disponível em: http://www.redproterra.org/ 